\title{
The Function of Negotiation in Iranian EFL Students' Vocabulary Acquisition
}

\author{
Hassan Soleimani (Corresponding author) \\ Department of Applied Linguistics, Payame Noor University, Tehran, Iran, POB: 19395-4697 \\ E-mail: Arshia.soleimani@gmail.com \\ Maryam Dadmohammadi \\ Department of Applied Linguistics, Payame Noor University, Tehran, Iran, POB: 19395-4697
}

Received: 13-04-2013

doi:10.7575/aiac.ijalel.v.2n.4p.161
Accepted: 20-05-2013

Published: 01-07-2013

URL: http://dx.doi.org/10.7575/aiac.ijalel.v.2n.4p.161

\begin{abstract}
Negotiation is believed to play a key role in language learning in general and vocabulary learning in particular. The present study aimed at investigating the effect of types of instructions (negotiation, non-negotiation, or in isolation) on learning and recalling of new words by Iranian learners. Using a quasi-experimental research design, 39 EFL students of a secondary school were sampled and assigned into three experimental groups: the input plus negotiated group (IPN), the input without negotiated group (IWN), and the elaborative, un-instructed input group (EUI). The first group had the chance for negotiated interaction; the second one received the input without any negotiation with their instructor and the last group received elaborative input without any interaction with their teachers. The groups were rated on their degree of comprehension and the acquisition of vocabulary items. The results revealed that negotiation had a non-significant effect over non-negotiation tasks. However, the results indicated that negotiation was significantly effective against uninstruction task. Thus, in acquisition and retention of new vocabulary, IPN group was not significantly different than IWN group, but they outperformed those learners who used their own strategy to learn new words (EUI).
\end{abstract}

Keywords: Acquisition of Vocabulary, Negotiated Input, Pre-modified Input, Elaboration, Enhancement.

\section{Introduction}

The importance of conversation in second language acquisition has been the focus of a host of researches over the past decades (Long, 1981, 1983; Pica, 1987; Gass, 1985, 1989). As Gass (1997, p.104) puts it, "Within the current research studies, conversation is not only a medium of practice; it is also the means by which learning take place. In other words, conversational interaction in second language acquisition forms the basis for the development of syntax; it is not merely a forum of grammatical structures". Through this development, nowadays the role of conversational interaction or negotiation has been investigated.

Inadequacy of sufficient meaningful input appears to be a major reason that hinders the development of learners' vocabulary knowledge in L2 formal contexts (Swan, 2005). Therefore, to some researchers the significance of vocabulary learning is linked to the fact that lexical items are at the heart of language teaching as far as syllabus design, assessment of learners, and learning resources are concerned (Candlin \& Mercer, 1988). As Azam, Chin, and Prakash (2010) put it, vocabulary is highly critical in language learning and acts like a communication toolbox with every word as a tool to be used at the right time, and learners take better chances of finding the appropriate tool for their purpose in case they master more tools. Nevertheless, possessing a great repertoire of words is not the ultimate purpose. Learning a new word means learning how to use the appropriate word at the appropriate time for effectiveness of communication.

Therefore, this study tries to examine the effects of different strategies on acquisition of vocabulary; how negotiation can be effective on long term memory while effective learning happens with the exchanges between learners and interlocutors, in order to assist learners "to check out the vocabulary" and to foreground background information (Hatch, 1978, p.431).

\section{Literature Review}

\subsection{Negotiation and Comprehension of Vocabulary}

Based on Pica's (1994) definition, "negotiation is the modification and restructuring of interaction that occurs when learners and their interlocutors anticipate, perceive, or experience difficulties in message comprehensibility" (p. 495). Furthermore, Del la Fuente (2002) argues that negotiation of meaning assists learners in obtaining comprehensible input that is specially modified for their individual circumstances and is a necessary condition for second language acquisition (SLA). Particularly, it "can promote acquisition because it allows learners to understand words and structures beyond their present level of competence and eventually enables them to incorporate them into their L2 production" (p. 83). 
In addition, the input hypothesis (Krashen, 1980) states that language acquisition happens only through comprehensible input, and implies that "acquisition" is the result of a subconscious process which appears to be highly similar to the process in which children pursue to acquire their mother tongue. To demonstrate the process through which interaction facilitates the objective, Long's (1981) interaction hypothesis seems plausible: language acquisition can be facilitated when we receive comprehensible input, and negotiation serves learners chances to access linguistic data to learn what is acceptable and what is not acceptable. Furthermore, Long (1983) maintains that negotiated interaction is helpful to orient learners' awareness to differences between learners' mother tongue and the second/foreign language. Contrary to studies conducted so far, the negotiation of meaning is to be studied more by researchers around the world in different contexts with different conditions if it is to be used for facilitating learning.

\subsection{Negotiation and Retention of Vocabulary}

Researchers in the field of meaning negotiation are also emphasizing that interaction involving meaning negotiation only facilitates acquisition; it does not cause acquisition to take place. In other words, as Mackey and Philip (1998) suggest, the interaction which is modified can merely trigger the learning. Moreover, Long (1996) argues that learners can comprehend input and infer the meanings of messages, which might result in successful comprehension but not acquisition. For acquisition to takes place, learners need to attend to the linguistic forms in the input and the meanings they realize and to compare what they notice with their own output. In other words, according to this position, it is 'processing input' rather than 'comprehending input' that is crucial for acquisition.

Furthermore, negotiation is considered as a way to help learners obtain comprehensible input with positive evidence (i.e. 'models of what is grammatical and acceptable' (Long, 1996). In this regard, Ellis (1992) states, "although there is now a rich body of descriptive research documenting how negotiation leads to input that has been modified in ways that can potentially promote acquisition there is still no research demonstrating a link between input and acquisition" (p. 9). Some researchers (e.g. Pica \& Doughty, 1985; Gass \& Varonis, 1984) are searching for strategies to understand the association between input and acquisition and find how comprehension results in acquisition and whether the input which is modified through interaction bolsters language acquisition or not.

To investigate the replication of the findings by researchers in the field concerning the effect of negotiation on the acquisition of lexical items by Iranian language learners, following up on Ellis and Takashima (1999), the following hypotheses were formulated:

Null Hypothesis 1: The input plus negotiation group does not outperform the input without negotiation group in acquisition of vocabulary.

Null Hypothesis 2: The input plus negotiation group does not outperform the elaborative un-instructed input group in acquisition of vocabulary.

\section{Methodology}

\subsection{Participants}

Participants in the study were 39 low intermediate Iranian EFL girl students from a non-profit secondary school in Tehran. Their first language was Persian, and they were between 12-13 years old. All participants had received approximately 150 hours of formal exposure to English as a foreign language; none of them had any experience of learning out of their school. The data were collected in the fall semester of 2012 with the help of two other teachers in the school. To homogenize the subjects in terms of their language proficiency, a pre-test was applied, then the participants were chosen randomly (cluster random sampling) and were assigned to the following three experimental groups; 1) the elaborative, un-instructed input group (EUI), 2) the input without negotiation group, (IWN), and 3) the input plus negotiation group (IPN). To homogenize the subjects in terms of their knowledge of target vocabulary items, a pretest was given to establish a set of lexical items unknown to the students.

\subsection{Materials}

The instruments used in data elicitation procedures were as follows:

1) Teaching materials (Treatment)
a. Matching items
b. Listening Comprehension
c. Negotiation group

2) Testing Materials;
a. Pre-test
b. Vocabulary Post-test 1
c. Vocabulary Post-test 2
d. Vocabulary Post-test 3

List of examples are given in Appendixes A to E.

\subsubsection{Teaching materials}

Teaching materials (Treatment) which was provided to all three groups contained new vocabulary items related to animals (see Appendixes B to D for some examples of these vocabulary items). They were applied separately to each group. Students' performances on each task provided a measure of comprehension of new words. The teaching materials consisted of 15 pictures of animals, based on the pre-test, which was not familiar to students. All pictures were extracted from a resource book for teachers, The Oxford Picture Dictionary (2008). Then, there were 14 definitions provided; one for each animal, followed by 14 names of animals. All definitions were chosen from the book National Geographic (2012). 


\subsubsection{Testing materials}

\section{a. The Pre-test}

The pre-test was applied to all groups one week prior to the commencement of the treatment. It included matching names of animals to their corresponding pictures. In order to increase the internal validity, the students were required to identify a set of words which were not known by any of them. The test consisted of 42 nouns (name of animals) extracted from teachers' resource book called The Oxford Picture Dictionary ( 2008). The participants were required to mark down the number of each picture to its correspondence animal. Fifteen out of 42 words were left blank, demonstrating that all participants didn't know the name of those 15 animals. The 14 items were: peacock, leopard, squirrel, parrot crow, rhinoceros, mosquito, hippopotamus, goose, rooster, camel, deer, skunk, and porcupine, bat. The reliability index of this test was estimated through Cronbach's alpha $(\mathrm{r}=0.78)$.

\section{b. Vocabulary Post-tests}

All three matching type post-tests were designed to measure the subjects' abilities in remembering the target words (name of the animals). The only difference between them was the order of definitions and name of animals. Applying Cronbach's alpha, the reliability index was calculated as .73 .

\subsection{Procedure}

The treatments were applied differently to three groups under study. After applying the pre-test participants who were not familiar with the 14 new vocabularies, were divided into three groups of 13 students each, based on their availability to the researcher. The treatment took the information gap format through matching items. To apply the treatment, all groups were presented with the same procedure; they all had the chance to see the picture of animals, but other parts were applied slightly different to each group.

For the EUI group, the participants had the chance to match a list of 14 words with a list of mixed definitions. Each learner read the definitions, and numbered the words from her list. For each definition, they were assigned two minutes. Their instructor, one of the researchers, explained that once they located the animals, they were not allowed to change their choices and in case of not knowing the answer, they had to leave the space blank. The activity carried out in 28 minutes by the group through reading only. The purpose of this activity was to measure the amount of learning on this type of instruction (reading alone without any interaction) on acquisition and retention.

The input without negotiation group was exposed to a listening comprehension task (of the information gap activity). Like the previous one, this activity was carried out in 28 minutes; for each definition 2 minutes were given. In this activity, the teacher gave instructions to the students to locate and identify the (previously mentioned) 14 target words. In the process, the instructor gave a definition by describing an animal followed by the phrase "Show me the..." and after each definition, the participants in $I W N$ group were asked to match and identify names of the animals on the sheet and place them on a worksheet numbered from 1 to 14 . In this activity the participants were not allowed to ask questions from their teacher (without negotiation) while they had the chance of listening each description and pronunciation clearly and correctly.

The process for IPN was very similar to the one-way activity except that participants were allowed to negotiate the meaning of the target items with their teachers. Negotiation with their teachers was allowed only through target language during which the participants were required to use repetition (negotiation moves). In order to transcribe the negotiation moves during the treatment, this activity was recorded. The participants were allowed to use repetition/negotiation moves; asking for a definition, asking for repetition, paraphrasing confirmation checks, comprehension checks, and clarification request.

\subsection{Data Analysis}

To examine the distribution of the collected data, both numerical and graphical techniques were applied along with measures of homogeneity and heterogeneity. Kolmogorov- Smirnov test and Shapiro-Wilk test were run and the results indicated normal distribution of the data. To measure the effects of types of instructions on three groups (EUI, IWN, IPN), a t-test was used for comparing the mean scores from the treatments applied to them (negotiated and nonnegotiated groups). To analyze the effects of types of instructions on retention, the collected data were submitted to a 3 $\times 3$ repeated measures analysis of variance (ANOVA) using a three between-subjects and three within-subjects factorial design. The between-subjects factor was type of instruction (EUI vs. IWN vs. IPN), whereas the within-subjects factor was time (Test 1 vs. Test 2 vs. Test 3 ).

\section{Results}

\subsection{Testing Hypothesis 1}

In order to test the first hypothesis, an independent $t$-test was used. Table 1 reveals that the group means are not significantly different while the significance value exceeds 0.05 . Therefore, no statistically significant difference was found $(\mathrm{t}(24)=1.36, p=.185)$ between the $I P N$ group and the $I W N$ group in comprehension and vocabulary acquisition scores of treatment test. 
Table 1. Independent Sample t-test of Input Plus Negotiation Group (IPN) and Input without Negotiation Group (IWN)

\begin{tabular}{llllllllll}
\hline & $\begin{array}{l}\text { Levine's Test for } \\
\text { Equality of } \\
\text { Variances }\end{array}$ & t-test equality of means & & & & & $\begin{array}{l}95 \% \\
\text { interval } \\
\text { difference }\end{array}$ & $\begin{array}{c}\text { confidence } \\
\text { of } \\
\text { the }\end{array}$ \\
\hline & $F$ & Sig. & T & df & $\begin{array}{l}\text { Sig.(2- } \\
\text { tailed) }\end{array}$ & $\begin{array}{l}\text { Mean } \\
\text { difference }\end{array}$ & $\begin{array}{l}\text { Std. error } \\
\text { difference }\end{array}$ & lower & upper \\
\hline $\begin{array}{l}\text { equal } \\
\text { variance } \\
\text { assumed }\end{array}$ & .375 & .546 & 1.364 & 24 & .185 & 1.00 & .73 & -.51 & 2.51 \\
\hline
\end{tabular}

\subsection{Testing Hypothesis 2}

Table 2 reveals a statistically significant difference $(\mathrm{t}(24)=3.17, \mathrm{P}=.004)$ between $I P N$ and EUI groups in comprehension and vocabulary acquisition scores of treatment test.

Table 2. Independent Sample t-test of Input Plus Negotiation Group (IPN) and Elaborative Uninstructed Input Group (EUI)

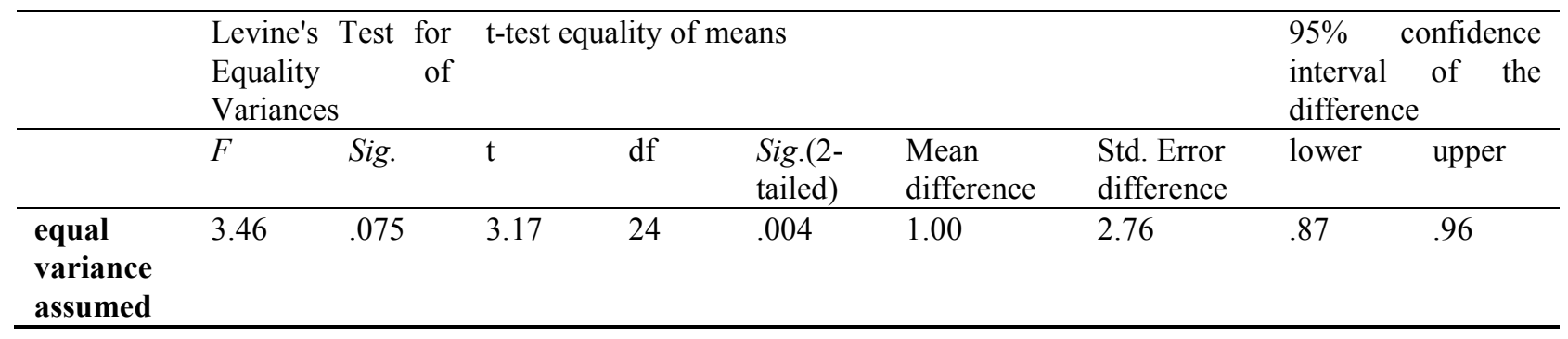

\subsection{Testing Hypothesis 1 for Three Post-tests}

Table 3 displays that all four multivariate tests, by contrast, do not reach conventional levels of statistical significance in interaction between post-test and experimental groups ( Sig < 0.05), meaning that there is no statistically significant difference between the performances of IPN and IWN because negotiation had a non-significant effect on these two types of instructions.

Table 3. Multivariate Tests on Hypothesis 1

\begin{tabular}{|c|c|c|c|c|c|c|}
\hline & Effect & Value & $\mathrm{F}$ & Hypothesis df & Error df & Sig. \\
\hline \multirow[t]{4}{*}{ Test } & \multirow{4}{*}{$\begin{array}{l}\text { Pillai's Trace } \\
\text { Wilks' Lambda } \\
\text { Hotelling's Trace } \\
\text { Roy's Largest Root }\end{array}$} & .739 & 20.790 (a) & 3.000 & \multirow{4}{*}{$\begin{array}{l}22.000 \\
22.000 \\
22.000 \\
22.000 \\
\end{array}$} & .00 \\
\hline & & .261 & 20.790 (a) & 3.000 & & .00 \\
\hline & & 2.835 & 20.790 (a) & 3.000 & & .00 \\
\hline & & 2.835 & 20.790 (a) & 3.000 & & .00 \\
\hline \multirow[t]{4}{*}{ test $*$ groups } & \multirow{4}{*}{$\begin{array}{l}\text { Pillai's Trace } \\
\text { Wilks' Lambda } \\
\text { Hotelling's Trace } \\
\text { Roy's Largest Root }\end{array}$} & .170 & $1.503(\mathrm{a})$ & 3.000 & \multirow{4}{*}{$\begin{array}{l}22.000 \\
22.000 \\
22.000 \\
22.000\end{array}$} & .24 \\
\hline & & .830 & $1.503(\mathrm{a})$ & 3.000 & & .24 \\
\hline & & .205 & $1.503(\mathrm{a})$ & 3.000 & & .24 \\
\hline & & .205 & $1.503(\mathrm{a})$ & 3.000 & & .24 \\
\hline
\end{tabular}

Table 4 measures "Between-Subjects Effects" and shows that there is no significant difference between the performances of $I P N$ and $I W N(\operatorname{sig}<0.05)$. So, negotiation had a non-significant effect on these two types of instructions: The first hypothesis is accepted.

Table 4. Tests of Between-Subjects Effects

\begin{tabular}{llllll}
\hline Source & $\begin{array}{l}\text { Type III Sum } \\
\text { of Squares }\end{array}$ & df & Mean Square & $F$ & Sig. \\
\hline Intercept & 10043.11 & 1 & 10043.11 & 588.11 & .00 \\
groups & 55.53 & 1 & 55.53 & 3.25 & .08 \\
Error & 409.84 & 24 & 17.07 & & \\
\hline
\end{tabular}




\subsection{Testing hypothesis 2 for Three Post-tests}

Table 5 demonstrates that there is a statistically significant difference $(F(1)=6.11, \mathrm{P}=.02)$ between the IPN and the EUI group in vocabulary learning scores. Hence, negotiation might have a significant effect on these two types of instructions: The second hypothesis is therefore rejected.

Table 5. Tests of Between-Subjects Effects

\begin{tabular}{|c|c|c|c|c|c|c|}
\hline Source & $\begin{array}{l}\text { Type III Sum } \\
\text { of Squares }\end{array}$ & $\overline{d f}$ & Mean Square & $F$ & Sig. & $\begin{array}{l}\text { Partial Eta } \\
\text { Squared }\end{array}$ \\
\hline Intercept & 9576.962 & 1 & 9576.962 & 609.053 & .000 & .962 \\
\hline Groups & 96.154 & 1 & 96.154 & 6.115 & .021 & .203 \\
\hline Error & 377.385 & 24 & 15.724 & & & \\
\hline
\end{tabular}

\section{Discussion}

\subsection{Discussion on Comprehension}

\subsubsection{Comprehension of groups IPN vs. IWN}

The results of this study indicated that reasonable levels of comprehension could be achieved in all three conditions (above 50\%). These scores supported Krashen and Terrell's (1983) claim that acquisition depends crucially on the input being comprehensible. Moreover, comprehensibility depends directly on the ability to recognize the meaning of key elements in the utterance. So, acquisition will not take place without comprehension of vocabulary. Thus, it could be construed that the degree of comprehension of learners is depended on the comprehensibility of sentences to learners.

Although learners in all three conditions achieved some acceptable comprehension scores, the opportunity to negotiate while doing the task appears to have helped the negotiation group attain the highest level of comprehension (11.92) 85\%. These findings support those of previous studies (Ellis, Tanaka, \& Yamazaki, 1994; Loschky 1994) and also for Long's interaction hypothesis $(1981,1983,1996)$ which they tried to answer how interactionally modified input contributes to acquisition. According to their research results, negotiation appears to enhance comprehension by contributing to learners' noticing the linguistic forms in the input and guaranteeing that the noticed linguistic form are within the processing capacity of language learners.

Comparing the results of comprehension scores of two groups of $I P N$ and $I W N$, it can be realized that they are in contrast with previous studies (Pica, Young, \& Doughty 1986; Loschky, 1994), while their results indicated that negotiation had a higher level of comprehension than other types. In this study, the results failed to demonstrate any significant advantage for negotiation over non-negotiation treatment (Difference in comprehension scores of these two groups was not statistically significant), as Ellis and Takashima (1999) has mentioned: "one explanation for this finding could be that whereas other studies did not control for the time taken to complete a task this study did. When learners were given the same amount of time to process, non-negotiated input as to negotiated input, their comprehension levels were essentially the same" (p.65).

Comparing present study with previous ones, it can be realized that one of the advantages of the result of this study over previous studies (i.e. Saitama study) is that most of the previous interaction activities were carried out in mother tongue which is not considered as negotiation. However, the present study was carried out only through target language. Another advantage of this study is the validity of results in question; due to influence of item familiarity of using same tests for the pre and post-tests which could have affected students' performance, post-test were based on the words that were unknown to participants in this study. Another advantage of the present study over studies such as Ellis might be in the amount of time given for task completion. Participants in Ellis's study had a total of 45 minutes to complete the task (no special time for each word), whereas in the present study they had 2 minutes per word negotiated, for a total of 28 minutes. The present study also ensured that participants in all three groups had relatively the same amount of time to do the task for each target words.

\subsubsection{Comprehension of groups IPN vs. EUI}

The results of comprehension scores for two groups of IPN and EUI were in line with those of others (Van Den Branden, 2000; Baleghizadeh \& Borzabadi, 2007). They confirm the hypothesis that negotiation improves comprehension to a considerable degree (difference in comprehension scores in two groups IPN and EUI was statistically significant). The underlying assumption could be that the second group (EUI) strategy to acquire vocabulary primarily occurs through the process of inferring word meaning. As some studies suggested, L2 learners left on their own commonly ignore the words which are not familiar, and they infer only when a specific need exists and consult sparingly and selectively (Bensoussan \& Laufer, 1984; Paribakht \& Wesche, 1997). Because attention to an unknown word seems to be a prerequisite for any learning to occur (Ellis et al., 1994; Schmidt, 1994), high rates of ignoring would thus severely limit the learning potential; as a result the degree of comprehension of group EUI was rather low. 


\subsection{Discussion on Time}

\subsubsection{Effect of types of instruction on short-term memory}

These results support those of previous studies (Ellis et al., 1994; Loschky, 1994) in that out of the three experimental groups, the one focusing largely on negotiation has shown that negotiation seems to have a positive effect on short-term memory: the mean score for group $I P N$ was higher than the other two groups. However, there wasn't any significant difference between scores of two $I P N$ and $I W N$ groups on the immediate post-test. These results were in line with the findings of Long (1991) and De la Feunte (2001). Long (1991) found out that there was no clear empirical basis for the claim that negotiated interaction results in acquisition. In addition, De la Feunte (2001) in his study found no significant effect for time nor any significant interaction between time and type of negotiation. To complete their findings, Sato (1986) also pointed out that conversational modification may facilitate communicative performance without facilitating the acquisition of new linguistic features.

The results of post-test1 for two groups IPN and IWN indicated that again the EUI group did not acquire well; this matter could be predicted based on the results of comprehension scores. The group which didn't comprehend the task properly (EUI), didn't do well on immediate post-test either.

\subsubsection{Effect of types of instruction on long-term memory}

Due to lack of research studies on effect of negotiation on long term memory, the results of this part cannot be compared with previous ones. The results of two delayed post-tests on groups $I P N$ and $I W N$ indicated that types of instructions do not have a clear implication on retention of new vocabularies; i.e. there was a big gap between the two groups of $I P N$ and $E U I$. The interesting matter in the result is that the mean average of all three experimental groups were above average point (more than 7), indicating that about half of them acquired the new vocabularies. Thus, half of the participants in three groups retained new words even after passing one month of treatment.

\section{Conclusion}

This study aimed at investigating the effect of negotiation on acquisition and comprehension of new vocabulary items. The results of this study confirm the results of previous researches regarding the positive effect of negotiation in comprehension and vocabulary acquisition (De la Fuente, 2002; Ellis \& He, 1999; Ellis, et al., 1994). However, the given results imply that controlling time during applying the tasks makes the comprehension of learners of two groups $(I P N$ vs. $I W N)$ to be almost the same; whereas the degree of comprehension fell at the time learners used their own strategy to acquire new words (EUI). This finding demonstrates that negotiation makes learners notice new words and as a result acquire better which is in accordance with the findings of Ellis and Takashima (1999) who concluded that negotiation may facilitate vocabulary acquisition by inducing learners to notice unknown words in the input (i.e., words that they need in order to understand their interlocutor's message) and also Schmidt (1990) who proposed the Noticing Hypothesis, according to which the emergence of new forms should be preceded by their being noticed in the input.

The effect of types of instruction on short and long term memory was another variable which was investigated in the study. Although there were a few studies in the literature examining instruction types, the result of this study might be used to imply that learners who were engaged in negotiation did not have any significant advantage over non-negotiated group; however, it had clear advantage over un-instructed group who just used their own strategy to learn new vocabularies.

To mention some suggestions for further research, the following points could be taken into account. The problem this study was faced with was the choice of context (it could be from more authentic texts that learners face in their daily lives); suggestion for future studies would be the need for a wider range of contexts such as stories and science texts based on different motivation and range of ages because different texts may have different effects on their readers. Another issue lies in the possible low involvement of participants due to the amount of motivation among them which is of great importance for consideration; in this study if the treatments were applied during the class time, the attention and motivation of students would be higher. Therefore to reach at more reliable results, researchers should try to find more innovative ways to involve their participants. In addition, since this study was applied only to girls ranging from 12-13, to get more comprehensible results, it is suggested that future studies be applied to different ages and genders.

\section{Acknowledgment}

The present research was a grant-based research project in Payame Noor University, Iran.

\section{References}

Azam, M., Chin, A., \& Prakash, N. (2010). The returns to English-Language skills in India. 2 (10),1-25. Retrieved from http://econstro.eu

Baleghizadeh, S., \& Borzabadi, A. D. (2007). The impact of two types of input modification on EFLreading comprehension: Linguistic versus interactional. Studies in Literature and Language, 1 (4), 20-28. Retrieved from www.sid.ir.

Bensoussan, M., \& Laufer, B. (1984). Lexical guessing in context in EFL reading comprehension. Journal of Research in Reading, 7, 15-32. doi: 10.1111/j.1467-9817.1984.tb00252.x. 
Candlin,C. N. \& Mercer, N. (Eds.) (1988). English language teaching in its social context. London: Rutledge.

De la Fuente, M. (2001). Negotiation and oral acquisition of L2 vocabulary: The roles of input and output in the receptive and productive acquisition of words. Studied in Second Language Acquisition, 22(01), 81-112. Retrieved from journals.cambridge.org.

Ellis, R. (1991a). The study of second language acquisition. New York: Oxford University Press.

Ellis, R. (1991b). Second language acquisition and language pedagogy. Clevedon, UK: Multilingual Matters.

Ellis, R., \& Takashima, H. (1999). Output enhancement and the acquisition of past tense. In R. Ellis (Ed.) Learning a second language through interaction (pp. 173-188). Amsterdam: Benjamins.

Ellis, R. \& He, X. (1999). The roles of modified input and output in the incidental acquisition of word meanings. Studies in Second Language Acquisition, 21, 285-301. Retrieved from http://journals.cambridge.org/action/displayAbstract;jsessionid=2F3BD080A2B6BE00803FD8A26666E7AD.journals?f romPage $=$ online\&aid $=36639$

Ellis, R., Tanaka, Y., \& Yamazaki, A. (1994), Classroom interaction, comprehension, and the acquisition of L2 word meanings. Language Learning, 44, 449-491.

Gass, S. M. (1985). Input in second language acquisition. In G. Madden and Carrylon, G. (Eds.). Applied Linguistics (pp.172-173). Rowley : Newbury House.

Gass, S. M. (1989), Language Universals and Second-Language Acquisition. Language Learning,39, 497-534. doi: 10.1111/j.1467-1770.1989.tb00901.x

Gass, S. M. (1997). Input, interaction, and the second language learner, Applied Linguistics. N.J.: Published by Mahwah.

Gass, S.M.\& Varonis, E. M. (1984), The effect of familiarity on the comprehensibility of nonnative speech. Language Learning, 34, 65-87. doi: 10.1111/j.1467-1770.1984.tb00996.

Hatch, E. (1978). Discourse analysis and second language acquisition. In E. Hatch (Ed.), Second Language Acquisition ( pp. 401-435). Rowley, Ma.: Newbury House.

Hulstijn, J. H. \& Schmidt, R. (1994). Consciousness in second language learning. Applied Linguistics. Retrieved from www.aila.info/ download/publications/review/ aila11. pdf Hulstijn, J.H. \& Schmidt, R

Krashen ,S. D. (1980). Second language acquisition and second language learning. California: Pergamon Press Inc .

Krashen, S. D., \& Terrell, T. D. (1983). The natural approach: Language acquisition in the classroom. Oxford: Pergamon.

Long, M. H. (1981). Input, interaction, and second language acquisition. Annals of the New York Academyof Sciences, 379, 259-278. doi: 10.1111/j.1749-6632.1981.tb42014.x.

TABLE I. Long, M. H. (1983). Native speaker/non-native speaker conversation and the negotiation of comprehensible input. Applied Linguistics. 4, 126-141. Retrieved from http:/www.mendeley.com/catalog/native-speaker-non-nativespeaker-conversation-negotiation-comprehensible-input

Long, M. H. (1991). Focus on form: a design feature in language teaching methodology. In: de Bot, K.,Ginsberg, R., Kramsch, C. (Eds.), Foreign Language Research in Cross-Cultural Perspective. JohnBenjamins, Amsterdam, (pp. 3952).

Long, M. (1996). The role of the linguistic environment in second language acquisition. In W. C. Ritchie \& T. K. Bhatia (Eds.).Second Language Acquisition (pp.413-468). New York: Academic Press.

Loschky, L. (1994). Comprehensible input and learning outcomes. Study in Second Language Acquisition,16,303323. Retrieved from http:// www.uji.es /bin/publ/edicions/jfi2/ compren .pdf (Loschky, L).

Mackey, A., \& Philip, J. (1998). Conversational interaction and second language development: Recasts, responses, and red herrings? Modern Language Journal, 82, 338-356. doi: 10.1111/j.1540-4781.1998.tb01211.x

National Geographic. (2012). National Geographic Society Press. Retrieved from

http://animals.nationalgeographic.com/animals/facts

Paribakht, T., \& Wesche, M. B. (1997). Lexical inferencing in a first and second language: Cross-linguistic dimensions. Multilingual Matters.

Pica , T. (1987). Second-language acquisition, social interaction, and the classroom. Applied Linguistics, 8(1), 3-21. doi: 10.1093/applin/8.1.3

Pica, T. (1994). Research on negotiation: What does it reveal about second-language learning conditions, processes, and outcomes? A Journal of Research in Language Studies, 44(3) 493-527. Retrieved from http://www.uwec.edu /.../ flg378picanegotiation \%20meaning\%20 (Pica , T.)

Pica, T., \& Doughty, C. (1985). The role of group work in classroom second language acquisition. Studies in Second Language Acquisition, 7(2), 233-248. doi:10.1017/S0272263100005398

Pica ,T., Young, R., \& Doughty, C. (1986). Making input comprehensible: Do interactional modifications help? ITL Review of Applied Linguistics, 72, 1-25. 
Sato, C. J. (1986). Conversation and interlanguage development: Rethinking the connection. In R. Day (Ed.), Talking to learn: Conversation in second language acquisition (pp.5-22). Rowley, MA: Newberry House.

Schmidt, R. (1990). The role of consciousness in second language learning. Applied $\quad$ Linguistics, 11(2), 129-158. Retrieved from http://www.corpus4u.org /forum/upload/ forum/2006062200592293.pdf.

Schmidt, R. (1994). Implicit learning and the cognitive unconscious: Of artificial grammars and SLA. In N. Ellis (Ed), Implicit and explicit learning of languages (pp.165-209). London: Academic Press.

Swan, M.( 2005). Legislation by hypothesis: The case of task-based instruction. Applied Linguistics,26(3): 376401.Retrieved from http:/www.azargrammar.com /assets /authorsCorner/notesQuotes/nq-bn_Swan.pdf.

Van Den Branden, K. (2000), Does negotiation of meaning promote reading comprehension? A study of multilingual primary school classes. Reading Research Quarterly, 35, 426-443. doi: 10.1598/RRQ.35.3.6.

\section{Appendix A}

\section{Wild Animals}

Name:

You are finding pictures of t-two animals. Please match the animals with their pictures. (Write number of each picture next to its word. One animal word is more than the pictures).

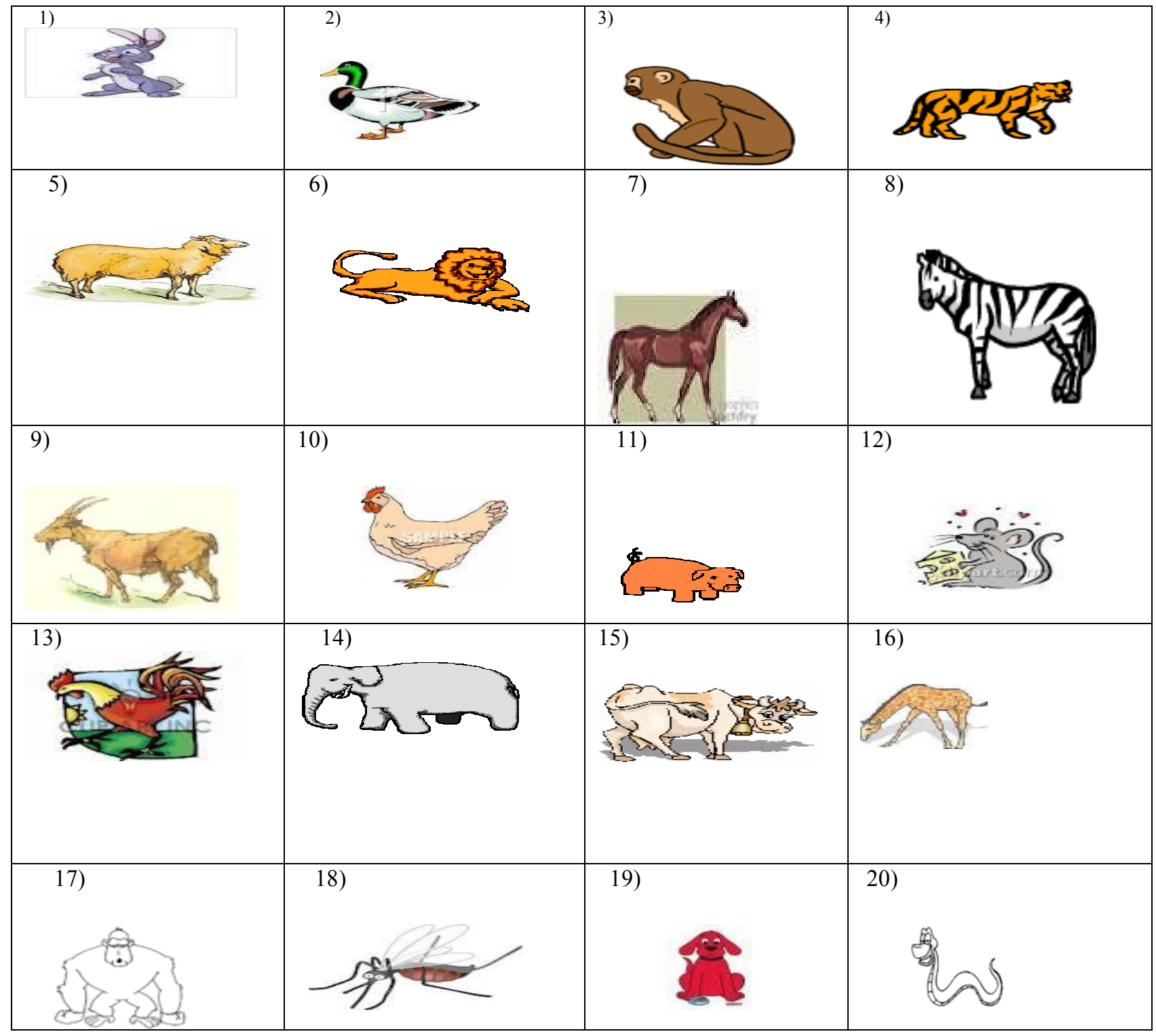




\begin{tabular}{|c|c|c|c|}
\hline 21) & 22) & 23) & 24) \\
\hline 25$)$ & 26) & 27) & 28) \\
\hline 29) & 30) & 31) & 32) \\
\hline 33) & 34) & 35) & 36) \\
\hline 37) & 38) & 39) & 40) \\
\hline 41) & 42) & & \\
\hline ---- horse & ----eagle & ---- tiger & ---- lion \\
\hline ---- sheep & ---- elephant & ---- giraffe & ----parakeet \\
\hline -----peacock & ---- alligator & ----- hen & ---- rabbit \\
\hline ---- pig & ---- monkey & ---- duck & ---- porcupine \\
\hline ----rhinoceros & ------mosquito & ---- cow & --hippopotamus \\
\hline ----cat & ---squirrel & ---- mouse & -----deer \\
\hline -----kangaroo & ---- otter & ----camel & ----owl \\
\hline ---- goat & ----leopard & -----koala & -----bat \\
\hline ----skunk & ---- rooster & ----zebra & ----crow \\
\hline ----dog & ---- gorilla & ---- penguin & ---- snake \\
\hline ----fish & ----bear & ----goose & \\
\hline
\end{tabular}

Thank you very much for your cooperation

\section{Appendix B}

\section{Direction for activity 1 (EUI Group)}

You will see the picture of fifteen animals (one picture is more), then you see the definitions of fourteen animals, and finally name of them. Try to match the number of fourteen animal names with their pictures. For each matching you will have a maximum of one (1) minute to locate it and place it, and you will not be able to change your choices once you have made it. If you do not know an answer, leave the space blank. 


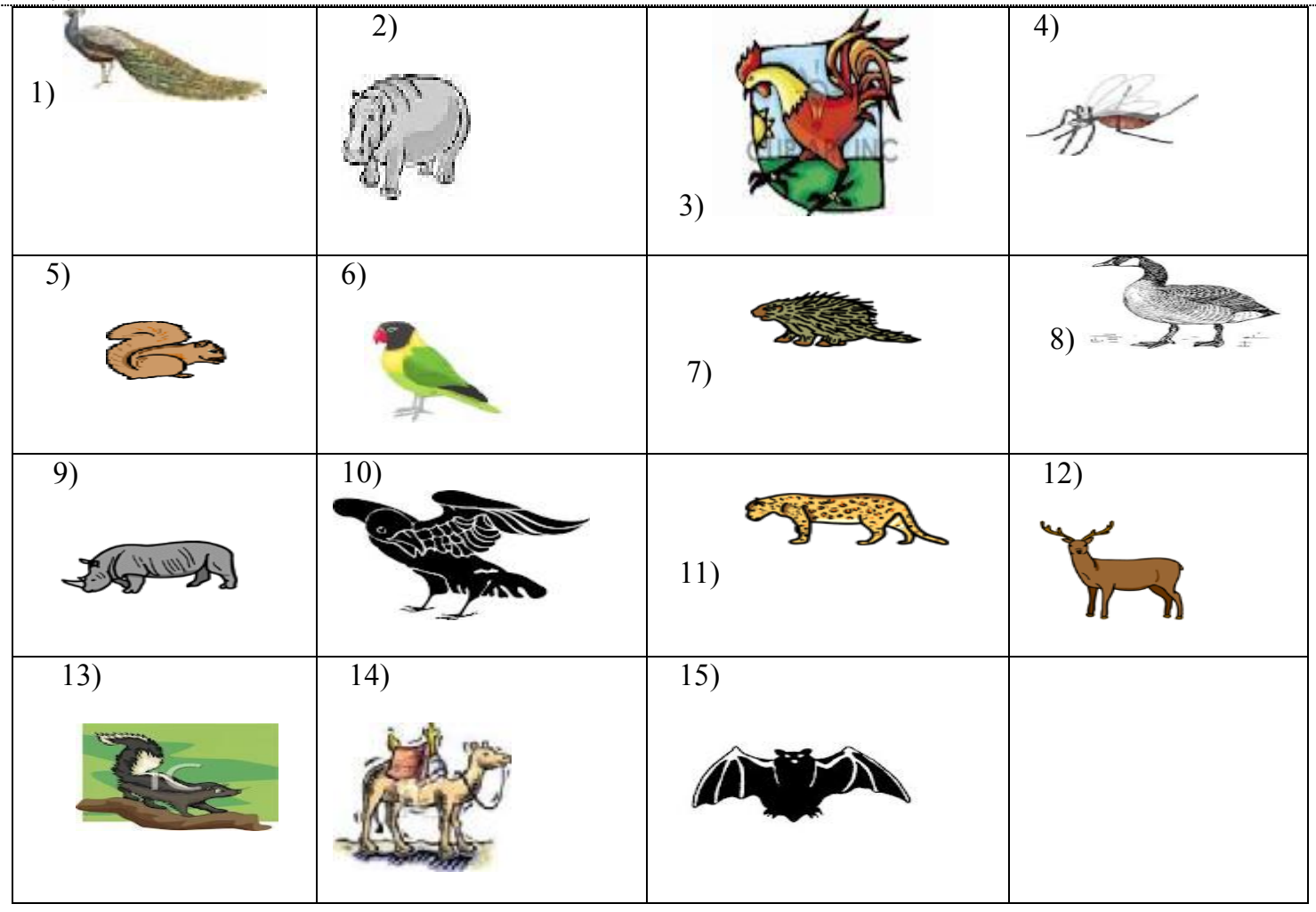

1) Show me the "rhinoceroses". He is a large heavy animal with thick rough, gray skin, square head and one horn on his nose. He lives in Africa so because of hot days there, he has to eat at night. He eats leaves and fruits from trees and loves playing in mud.

2) Show me the "skunk". He is a cat-sized animal with a black coat and a wide white stripe down the middle of his body. When he sees his enemies, pulls his large tail up and sprays a bad smell which makes his enemies no real damage but makes them escape from him. He produces this smell to defend himself so don't have to fight.

3) Show me the "peacock". He is a large, royal-looking bird. He is known for his beautiful and long tail feathers. The feathers are mixed with blue and green colors and can be arched into a magnificent fan that reaches across his back and touches the ground on either side.

4) Show me the "squirrel". He is a small animal with a long tail. He lives in trees and eats nuts. He has four front teeth that never stop growing so he has to bite something constantly. He likes jumping from branch to branch of trees.

5) Show me the "crow". He is a large black bird. He has a loud voice which is not as melodic as other birds. Most people don't like his voice. He eats almost everything; seeds, fruits, nuts, eggs..., even garbage.

6) Show me the "porcupine". He is a small animal with soft hair, but his back, sides and tail mixed with sharp quills (needles). The quills typically lays flat until he feels threatened, then they jump to shoot toward his enemies.

7) Show me the "parrot". He is a colored bird with curved beak .He can learn to copy human speech. He eats fruit, flowers, nuts, seeds, and some small creatures such as insects. He usually lives in warm climate like India, Africa.

8) Show me the "goose". He is a large feathery bird. He is a water bird like duck but larger. He makes loud noises, and flies to warmer places in "U" shape group.

9) Show me the "mosquito". He is a small flying insect that bites and sucks the blood of people and animals, making people itch and sometimes spread diseases like malaria.

10) Show me the "hippopotamus". He is a large African animal with a big head, fat body, and thick gray skin. He loves water very much and that's the reason that his name in Greek means "river horse". He puts his body in water to keep it cool in hot African summer. 
11) Show me the "camel". He is a large animal with a long neck and one or two humps on his back. The humps are storing fat which can be converted to water and energy during the long periods of travel without water; even in very difficult desert conditions.

12) Show me the "rooster". He is father of the chicken. In the morning his song makes waking up the people. He is larger, usually more brightly colored, and has larger combs on top of his head compared to mother chicken.

13) Show me the "deer". He is a large wild animal that lives in forests. His horns look like tree branches. He eats grass and vegetables. He runs so quickly that even his enemies cannot catch him very easily.

14) Show me the "leopard". He is a large and strong wild cat with yellow fur and black spots that hunts in the jungle. He lives in Africa and south Asia. Be careful in jungle because he eats even people!

\begin{tabular}{|l|l|l|l|}
\hline -----peacock & ----leopard & ---squirrel & ----parrot \\
\hline ----crow & ----rhinoceros & -----mosquito & --hippopotamus \\
\hline ----goose & ---- rooster & ----camel & ----deer \\
\hline ----skunk & ---- porcupine & & \\
\hline
\end{tabular}

\section{Appendix C}

\section{Directions for activity 1 (IWN group)}

In this activity you will see the picture of fifteen animals (one picture is more), then you will hear the definitions of fourteen animals, and finally name of them. Try to match the animals and place their numbers on this sheet into the table provided. No interaction with your teacher will be allowed, so listen carefully. For each listening you will have a maximum of one (1) minute to locate it and place it, and you will not be able to change your choice once you have made it. If you do not know an answer, leave the space blank. This activity will be repeated one more time, but the order in which the instructions are given will be different.

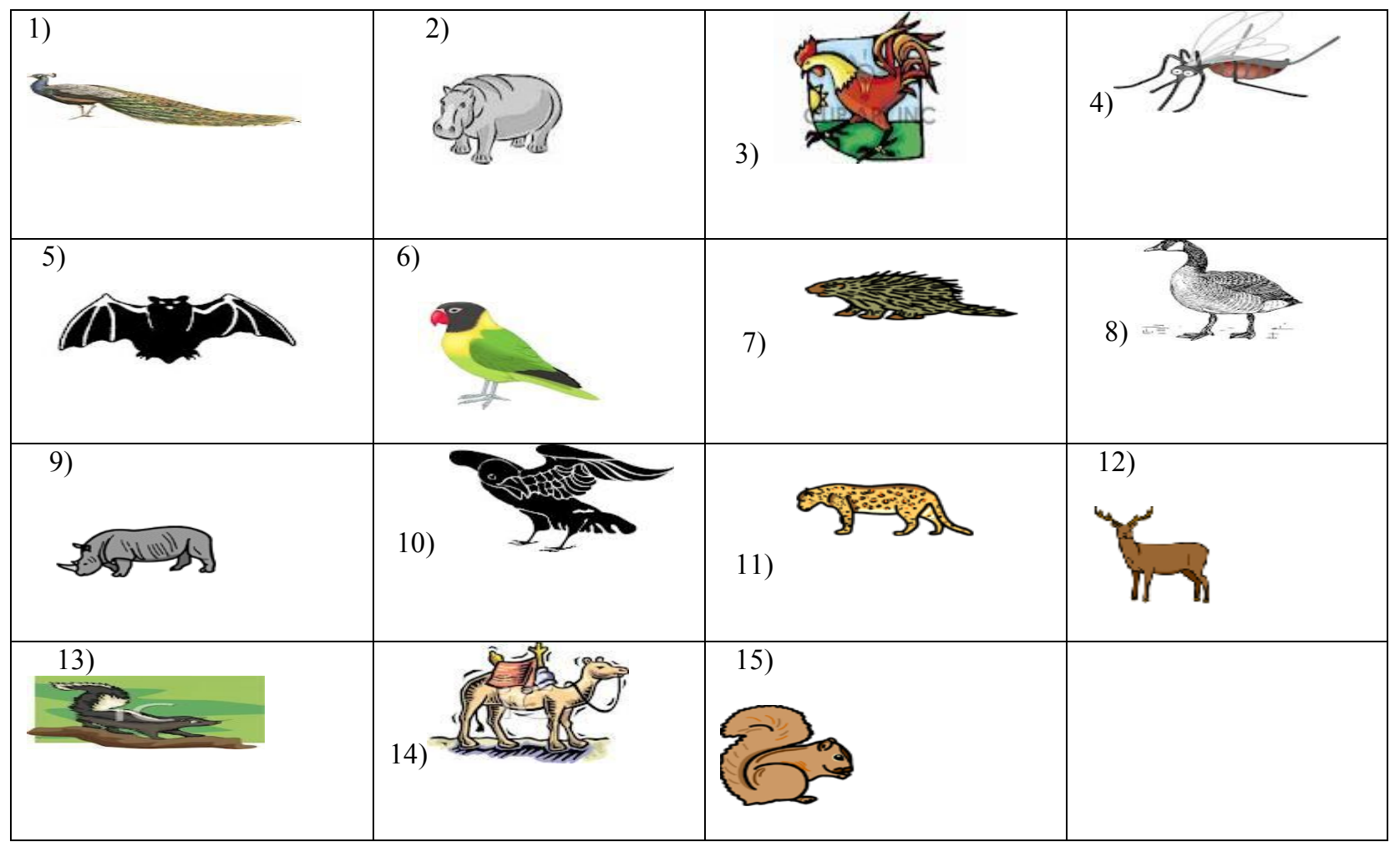

\begin{tabular}{|l|l|l|l|}
\hline----- peacock & ----leopard & ---squirrel & ----parrot \\
\hline ----crow & ----rhinoceros & -----mosquito & --hippopotamus \\
\hline---- goose & ---- rooster & ----camel & ----deer \\
\hline---- skunk & ---- porcupine & & \\
\hline
\end{tabular}




\section{Appendix D}

\section{Directions for Activity 1 (IPN Group)}

In this activity you will see the picture of fifteen animals (one picture is more), then you will hear the definitions of fourteen animals, and finally name of them. Your teacher will instruct you to find the animals and place their numbers on this sheet into the table provided.You can interact with your evaluator so please ask all the questions you need in English in order to clarify meanings and perform the task successfully. For each word you will have a maximum of one (1) minute to ask questions, and you will not be able to change your choice once you have made it. This activity will be repeated one more time, but the order in which the instructions are given will be different.

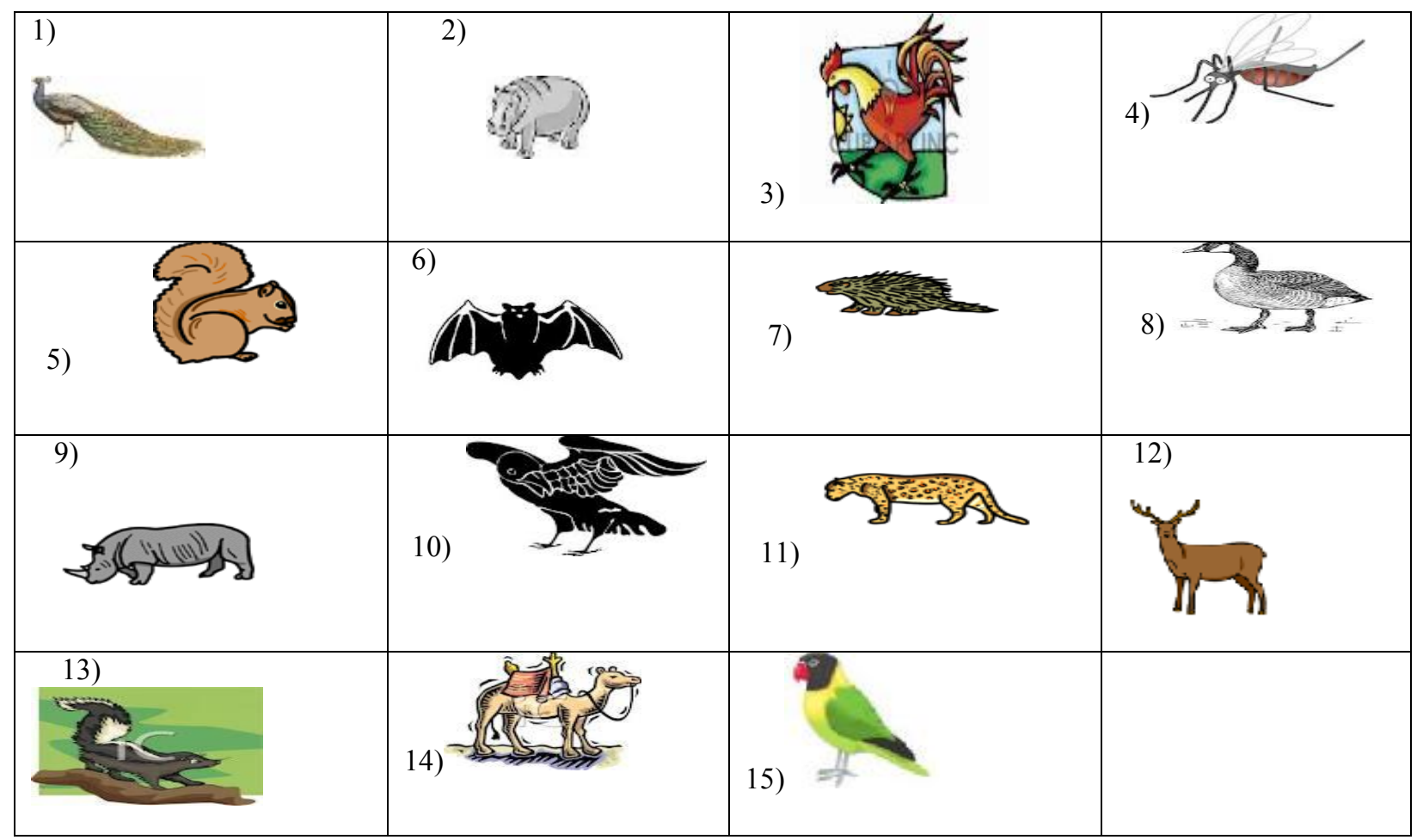

\begin{tabular}{|l|l|l|l|}
\hline -----peacock & ----leopard & ---squirrel & ----parrot \\
\hline ----crow & ----rhinoceros & -----mosquito & --hippopotamus \\
\hline ----goose & ---- rooster & ----camel & ----deer \\
\hline ----skunk & ---- porcupine & & \\
\hline
\end{tabular}

\section{Appendix E}

\section{$\underline{\text { Post-test }}$}

You are finding the description of 14 animals. Please match the descriptions with their names. (Write number of each description next to its name).

1) I am a small animal with a long tail. I live in trees and eat nuts. I have four front teeth that never stop growing so I have to bite something constantly. I like jumping from branch to branch of trees.

Guess who am I? I am a (n)

2) I am a large wild animal that live in forests. My horns look like tree branches. I eat grass and vegetables. I run quickly that even my enemies cannot catch me very easily.

Guess who am I? I am a (n)

3) I am a colored bird with curved beak .I can learn to copy human speech. I eat fruit, flowers, nuts, seeds, and some small creatures such as insects. I usually live in warm climate like India, Africa.

Guess who am I? I am a (n) 
4) I am a large, royal-looking bird. I am known for my beautiful and long tail feathers. The feathers are mixed with blue and green colors and can be arched into a magnificent fan that reaches across my back and touches the ground on either side.

Guess who am I? I am a (n)

5) I am a large black bird. I have a loud voice which is not as melodic as other birds. Most people don't like my voice. I eat almost everything; seeds, fruits, nuts, eggs..., even garbage.

Guess who am I? I am a (n)

6) I am a small animal with soft hair, but my back, sides and tail mixed with sharp quills (needles). These quills typically lay flat until I feel threatened, then they jump to shoot toward my enemies.

Guess who am I? I am a (n)

7) I am a large animal with a long neck and one or two humps on my back. The humps are storing fat which can be converted to water and energy during the long periods of travel without water; even in very difficult desert conditions.

Guess who am I? I am a (n)

8) I am a large feathery bird. I am a water bird like duck but larger. I make loud noises, and fly to warmer places in "U" shape group.

Guess who am I? I am a (n)

9) I am a small flying insect that bite and suck the blood of people and animals, making people itch and sometimes spread diseases like malaria.

Guess who am I? I am a (n)

10) I am a large African animal with a big head, fat body, and thick gray skin. I love water very much and that's the reason that my name in Greek means "river horse". I put my body in water to keep it cool in hot African summer.

Guess who am I? I am a (n)

11) I am a large and strong wild cat with yellow fur and black spots that hunts in the jungle. I live in Africa and south Asia. Be careful in jungle because I eat even people! Guess who am I? I am a (n)

12) I am father of the chicken. In the morning my song wakes up the people. I am larger, usually more brightly colored, and have larger combs on top of my head compared to mother chicken.

Guess who am I? I am a (n)

13) I am a large heavy animal with thick rough, gray skin, square head and one horn on my nose. I live in Africa so because of hot days there, I have to eat at night. I eat leaves and fruits from trees and love playing in mud.

Guess who am I? I am a (n)

14) I am a cat-sized animal with a black coat and a wide white stripe down the middle of my body. When I see my enemies, pull my large tail up and spray a bad smell which makes them no real damage but make them escape from me. I produce this smell to defend myself so don't have to fight.

Guess who am I? I am a (n)

\begin{tabular}{|l|l|l|l|}
\hline ------peacock & ----leopard & ---squirrel & ----parrot \\
\hline ----crow & ----rhinoceros & -----mosquito & --hippopotamus \\
\hline ----goose & ---- rooster & ----camel & ----deer \\
\hline ----skunk & ---- porcupine & -----owl & \\
\hline
\end{tabular}

